\title{
Selective Incivility: Immigrant Groups Experience Subtle Workplace Discrimination at Different Rates
}

\author{
Franciska Krings and Claire Johnston \\ University of Lausanne
}

\author{
Steve Binggeli \\ Rice University
}

\author{
Christian Maggiori \\ University of Lausanne
}

\begin{abstract}
Immigrants play an increasingly important role in local labor markets. Not only do they grow steadily in number but also in cultural, educational, and skill diversity, underlining the necessity to distinguish between immigrant groups when studying discrimination against immigrants. We examined immigrant employees' subtle discrimination experiences in a representative sample in Switzerland, controlling for dispositional influences. Results showed that mainly members of highly competitive immigrant groups, from immediate neighbor countries, experienced workplace incivility and that these incivility experiences were related to higher likelihoods of perceived discrimination at work. This research confirms recent accounts that successful but disliked groups are particularly likely to experience subtle interpersonal discrimination.
\end{abstract}

Keywords: discrimination, incivility, immigrants, diversity

During the last decade, immigrants accounted for $70 \%$ of the increase of the workforce in Europe and for $47 \%$ in the United States (OECD, 2012a). Currently, they make up $16 \%$ of the workforce in the United States, $21 \%$ in Canada, and $27 \%$ in Switzerland, that is, the country where the present study was conducted (OECD, 2012b; Swiss Federal Statistics Office [SFSO], 2012). Immigrants have not only increased in number but also in cultural, educational, and skill diversity. For example, in 2000, most immigrants to the United States came from Hispanic countries, while in 2012 most immigrants came from Asia (Pew Research Center, 2012). Similarly, most of the earlier immigrants to Switzerland came from Southern Europe while today most immigrants come from Western European neighbor countries (Liebig, Kohls, \& Krause, 2012). These new immigrants have higher education levels and work in higher-status positions than earlier immigrants,

This article was published Online First August 18, 2014.

Franciska Krings, Faculty of Business and Economics, Department of Organizational Behavior, University of Lausanne, Lausanne, Switzerland; Claire Johnston and Christian Maggiori, National Competence Center in Research LIVES, University of Lausanne; Steve Binggeli, Department of Psychology, Rice University.

This research is part of the National Competence Center in Research LIVES, which is financed by the Swiss National Science Foundation. The authors are grateful to the Swiss National Science Foundation for its financial support. An earlier version of this article was presented at the 28th annual Society for Industrial and Organizational Psychology conference in Houston, Texas, April 2013.

Correspondence concerning this article should be addressed to Franciska Krings, Faculty of Business and Economics, Department of Organizational Behavior, University of Lausanne, 1015 Lausanne, Switzerland. E-mail: franciska.krings@unil.ch responding to many nations' increasing demand for highly skilled labor.

In research on workplace discrimination, immigrants have received little attention (Binggeli, Dietz, \& Krings, 2013). However, theories of prejudice and discrimination suggest that immigrants are likely targets of subtle forms of prejudice and discriminatory behaviors. Subtle, interpersonal discriminatory behaviors particularly target members of groups perceived as competent competitors (Cortina, 2008; Fiske, Cuddy, Glick, \& Xu, 2002). Hence, members of recent, highly skilled immigrant groups may experience more subtle discrimination than members of earlier, less skilled immigrant groups.

This was the starting point of the present research. It studied the experience of subtle workplace discrimination of immigrants and locals in a representative sample of employees in Switzerland. We focused on the experience of incivility, that is, of being the target of low-intensity discourteous interpersonal behaviors (Andersson \& Pearson, 1999). Incivilities are general but if they selectively target a minority group, grounded in diffuse antiminority feelings and stereotypes, they become a form of subtle interpersonal discrimination (Cortina, 2008). Because immigrants are targets of subtle prejudice and mainly associated with mixed, ambivalent stereotypes (Lee \& Fiske, 2006; Pettigrew \& Meertens, 1995), we expected immigrants to experience more incivility than locals. Further, theories of intergroup competition and stereotype content suggest that groups perceived as competitive and highly competent but as little likable, experience more subtle discrimination (Esses, Dovidio, Jackson, \& Armstrong, 2001; Fiske et al., 2002). Indeed, depending on their national origin, immigrant groups differ remarkably on perceived competence and likability (Lee \& Fiske, 2006). Hence, we expected immigrants belonging to groups perceived as highly competent but less likable to be particularly frequent targets of incivility. Of importance, these differences are 
expected above and beyond other personal characteristics (e.g., neuroticism) related to experiencing incivility and discrimination.

In the remainder of the introduction, we first outline the concept of selective workplace incivility as subtle discrimination against immigrant employees. Then, we describe how differences in stereotypes of national or ethnic groups may affect rates of experienced workplace incivility. Finally, we discuss possible relations between experiences of incivility and perceived discrimination.

\section{Selective Incivility as Subtle Discrimination Against Immigrants}

At the base of subtle discrimination are subtle prejudice and stereotypes (Cortina, 2008; Dipboye \& Halverson, 2004). Subtle prejudices encompass the belief that discrimination is a thing of the past, that minority groups' claims are unfair and that there are large (cultural) differences between social groups (Gaertner \& Dovidio, 1986; McConahay, 1986; Swim, Aikin, Hall, \& Hunter, 1995). These beliefs present a subtle, ostensibly rational form of expressing prejudice and help people preserve a nonprejudiced self-image. In a similar vein, recent work on the content of stereotypes has shown that most group stereotypes are mixed, that is, contain positive (e.g., trustworthy) and negative (e.g., incompetent) elements (Fiske et al., 2002). Because of the positive elements, many stereotypical beliefs are subjectively experienced as nonprejudicial (Glick \& Fiske, 1996, 2001). Subtle prejudices and mixed stereotypes result in interpersonal rather than in formal discrimination (Hebl, Foster, Mannix, \& Dovidio, 2002). Interpersonal discrimination emerges in social interactions at work, including verbal, nonverbal, and paraverbal behaviors, and is subtler and more compatible with a nonprejudiced self-image than formal, more direct discrimination, which occurs, for example, at hiring or promotion and is, in most countries, against the law.

Cortina (2008) recently proposed that workplace incivility may take the form of subtle, interpersonal discrimination. Incivility is "low-intensity deviant behavior with ambiguous intent to harm the target, in violation of workplace norms for mutual respect. Uncivil behaviors are characteristically rude and discourteous, displaying a lack of regard for others" (Andersson \& Pearson, 1999, p. 457). It encompasses behaviors such as interrupting, ignoring or using a condescending tone. Despite their low-intensity, these behaviors have several detrimental consequences for targets, such as greater levels of stress, lower commitment and job satisfaction, or higher quit rates (Pearson \& Porath, 2004).

When incivility selectively targets members of minority groups, based on ambivalent antiminority feelings and stereotypes, it becomes discrimination (Cortina, 2008). This discrimination is subtle because of the ambiguous nature and apparent neutrality of the uncivil behaviors, instigators easily find (consciously or not) nonprejudicial explanations for their conduct (e.g., "I have too much work"). Selective incivility is hence a particularly well-suited means by which people may mistreat minorities without damaging their nonprejudiced image of themselves and toward others.

Recent studies provide first empirical evidence for such targeted incivilities: Women and people of color reported higher rates of uncivil treatment at work than men and Whites (Cortina et al., 2002; Cortina, Kabat-Farr, Leskinen, Huerta, \& Magley, 2011). In this research, we examined incidence rates of incivility for immigrants, compared with locals. Several elements suggest that immi- grants are likely targets. First, immigrants are targets of subtle prejudice (Akrami, Ekehammar, \& Araya, 2000; Pettigrew \& Meertens, 1995). Further, immigrants are mainly associated with ambivalent or mixed stereotypes, which encompass positive and negative features: Most immigrant groups are either perceived as incompetent but nice (e.g., Irish immigrants in the United States or Portuguese immigrants in Switzerland) or as competent but less likable (e.g., Asian immigrants in the United States or German immigrants in Switzerland) (Binggeli, Krings, \& Sczesny, in press; Lee \& Fiske, 2006). Subtle prejudice toward immigrants and mixed immigrant stereotypes provide the attitudinal and cognitive basis for subtle mistreatments at work. Second, earlier research on employment discrimination has shown that subtle prejudice indeed fosters discrimination against immigrants (Krings \& Olivares, 2007; Petersen \& Dietz, 2005). Finally, immigrants themselves report feeling discriminated against at work (Jasinskaja-Lahti, Liebkind, \& Perhoniemi, 2007; Kravitz \& Klineberg, 2000). Therefore, we expected the following:

Hypothesis 1: Immigrants report more experiences of workplace incivility than locals.

When analyzing differences between social groups, it is important to control for personality differences because certain characteristics of the target may contribute to the likelihood of experiencing discriminatory behaviors (Milam, Spitzmueller, \& Penney, 2009). For example, people low in agreeableness or high in neuroticism tend to be distrustful and display discourteous, bothersome behaviors (McCrae \& Costa, 1987). Thus, they may be more likely to perceive an event as rude, as well as to provoke uncivil behaviors from others as a reaction to their own behaviors. Indeed, people low in agreeableness and high in neuroticism experience more incivility (Milam et al., 2009). As a consequence, for testing our hypotheses, we controlled for employees' level of neuroticism and agreeableness, to assure that effects of group membership would persist, above and beyond those of individual differences.

\section{Some Immigrant Groups Are More Likely Targets of Incivility Than Others}

The global stereotype of immigrants as a group is that they are untrustworthy and incompetent (Eckes, 2002). However, recent work suggests that immigrants should not be treated as one entity: Stereotypes of immigrants differ remarkably between groups depending on the group's country of origin. Drawing on the stereotype content model, Lee and Fiske (2006) showed that perceptions of warmth (being good-natured, kind) and competence (being intelligent, skillful) of immigrant groups differed as a function of the groups' national origin. These perceptions result from sociostructural relations between locals and immigrant groups: Immigrant groups viewed as high status are perceived as high in competence and groups viewed as competing for resources are perceived as lacking warmth.

Importantly, different warmth and competence stereotypes give rise to more or less hostile behaviors (Cuddy, Fiske, \& Glick, 2007; Sibley, 2011). As outlined above, mixed stereotypes provide the foundation for subtle behaviors undermining equality. Hence, most immigrants should be likely targets of subtle mistreatments at work. However, groups perceived as competent but cold should be somewhat more targeted than groups perceived as incompetent but 
nice because the former elicit more hostility, especially when they gain more status or power (e.g., when they are successful in the labor market) than the latter (Cuddy, Fiske, \& Glick, 2008; Fiske et al., 2002). The clear competence and ability of these groups makes it difficult to blatantly discriminate against them. However, their perceived lack of interpersonal warmth and sociability makes it easier to subtly discriminate against them, in everyday social interactions at work (e.g., by addressing them in unprofessional terms). Similarly, Cortina (2008) argued that professionally successful women and black professionals are particularly prone to experience selective incivility because they are considered (excessively) competent and ambitious, ultimately threatening the dominant position of the majority.

These considerations suggest that immigrants belonging to national or ethnic groups perceived as competent but cold are more likely targets of workplace incivility. In Switzerland, it is immigrants from the immediate neighbor countries (Germany and France) that receive this stereotype. These immigrants are perceived as highly competent but less likable, as demonstrated by a recent analysis of warmth and competence stereotypes of the most salient immigrant groups in Switzerland (Binggeli et al., in press). Four groups emerged from this analysis: (1) immigrants perceived as low in competence and low in warmth, comprising immigrants from the Balkans, Turkey, and Eastern Europe; (2) immigrants perceived as moderately warm but incompetent, with immigrants from Africa; (3) immigrants perceived as highly warm but moderately competent, comprising immigrants from Southern Europe; and, finally, (4) immigrants perceived as highly competent but lacking warmth, consisting of German and French immigrants. Warmth perceptions of German immigrants were particularly low in the German-speaking region of Switzerland, whereas warmth perceptions of French immigrants were particularly low in the French-speaking region.

The number of German and French immigrants has multiplied since Switzerland introduced freedom of movement for people from European-Union member states in 2002 (Liebig et al., 2012). Since then, no other immigrant group has increased in size as considerably and as rapidly as they have. Today, these immigrants are among the three largest immigrant groups in Switzerland. Compared with immigrants from other nations, they have a strong competitive advantage: They speak one of the two main national languages of Switzerland (i.e., German or French) and tend to be highly educated. Hence, it is no surprise that they have higher employment rates and are more likely to work in high status positions than any other immigrant group, and even than locals (SFSO, 2012). The competitiveness of these groups has led to a heated public debate, revealing that they are perceived as a threat and strong competitors for desirable resources such as jobs. Indeed, the perceived competitiveness of these groups explains their low levels of likability or perceived warmth (Binggeli, Krings, \& Sczesny, 2013). Taken together, in certain ways, German and French immigrants are comparable with Asians in the United States, which is a group that too is very successful on the labor market and that too is stereotyped as excessively competitive and highly competent, but as lacking sociability (Lee \& Fiske, 2006; Lin, Kwang, Cheung, \& Fiske, 2005).

In summary, based on German and French immigrants' highcompetence or low-warmth stereotype as well as their strong competitiveness, we expected the following:
Hypothesis 2: Immigrants from France and Germany report more experiences of workplace incivility than immigrants of other nations, so that German and French immigrants report the highest rate of incivility, followed by other immigrants, followed by locals.

\section{Linking Selective Incivility and Perceived Discrimination}

To what extent incivility experiences fuel perceptions of discrimination by the target is an open question. On the one hand, given the apparently neutral and ambiguous nature of incivility, it may be difficult for targets to recognize it as discrimination (Cortina, 2008). Targets may be just as ready to find nonprejudicial explanations for receiving uncivil treatment as instigators do for acting uncivil. On the other hand, over time, targets may realize that they are mistreated more frequently than their colleagues and come to realize that being the target is related their minority status. Moreover, if incivility selectively targets their group, they are likely to observe that other members of their group are treated similarly, further highlighting the discriminatory component and increasing the probability of feeling discriminated against.

To our knowledge, the relation between selective incivility and perceived discrimination has not been empirically tested yet. In the light of the considerations above, we analyzed the relation in an exploratory manner.

\section{Method}

\section{Participants and Procedure}

This study is part of a larger, longitudinal project, hosted by the National Centre of Competence in Research LIVES. Data for this study are from the first data collection wave in 2012. A representative sample of the working age population living in Switzerland was drawn based on a random sample from the Swiss Federal Statistics Office. Sampling was targeted at the two largest linguistic regions, the German-speaking and the French-speaking regions, and was representative in terms of age, gender, linguistic region, and nationality.

Participants $(n=2,001)$ completed a research protocol consisting of two steps. The first part, completed by a computer-assisted telephone interview or as an online questionnaire, aimed to explain the goal of the study, verify the inclusion criteria (e.g., age between 25 and 55, living in Switzerland) and determine the participants' professional situation and biography. The second part, completed via a paper-pencil or as an online questionnaire, assessed aspects of the work and social environment, personal characteristics and general outcomes. Most participants (79\%) completed both parts online. Most of the local and immigrant participants $(67 \%)$ answered the questionnaire in German. This proportion corresponds to the percentage of people living in the German part, that is, in Switzerland's largest linguistic region.

The University of Lausanne does not have an institutional review board for psychology or social science research. This research thus applied the ethical standards of the Swiss Psychological Society. Accordingly, the survey avoided any treatment that might have a detrimental effect on the well-being or integrity of participants. During the first part, participants were informed 
about the purpose of the study and were ensured their data would remain confidential. Agreement to participate by responding to the questions and filling out the questionnaire was taken as consent.

For the present research, we included only employed participants. The resulting sample consisted of 1,661 employees, of which 1,359 were Swiss and 302 were immigrants. Hence, $18 \%$ of participants were immigrants. This is somewhat lower than the current percentage of immigrants in the Swiss workforce $(27 \%)$ and can be explained by the study's inclusion criteria (e.g., only workers between age 25 and 55 were included) and by the fact that participants needed sufficient proficiency in French or German to participate.

Of the immigrant participants, $43.4 \%$ came from France or Germany. The remaining immigrants, grouped into one category for the following analyses, came from various countries: $24 \%$ came from Southern European countries (e.g., Portugal, Spain), $11 \%$ from Northern European countries (e.g., Norway, Sweden), $8 \%$ from the Balkans (e.g., Bosnia, Croatia) or Turkey, $4 \%$ from countries in Eastern Europe or central Asia (e.g., Ukraine, Russia), and the rest $(9.6 \%)$ from various countries in Asia, Northern or Southern America. Most (63\%) had permanent residence permits, $37 \%$ had annual residence permits that are easily renewed if immigrants are still employed.

Half of the local (49\%) and immigrant participants (48\%) were women. Locals were on average 42.15 years $(S D=8.63)$ and immigrants 40 years $(S D=7.87)$ old. Mean educational levels (ranging from 1 = obligatory schooling, 4 = degree in higher education) were $2.80(S D=0.97)$ for locals and $2.90(S D=1.14)$ for immigrants. Furthermore, educational mean level comparisons suggest that immigrants from Germany and France were better educated, $M=3.31, S D=0.91$, than immigrants of other nationalities, $M=2.61, S D=1.21$, or locals. This pattern mirrors the current Swiss labor market (Liebig et al., 2012). However, these numbers should be interpreted with caution, for two reasons. First, 120 participants (95 locals and 26 immigrants) did not indicate their education. Second, participants indicated their educational level with predefined categories that are used in the Swiss education system, which can be problematic because of differences in educational systems between countries.
The majority of locals $(75.5 \%)$ and immigrants $(84.9 \%)$ were employed at an activity rate of $80 \%$ and more, that is, they worked between $36.2(80 \%)$ and $42 \mathrm{hr}(100 \%)$ per week. A bit less than half of the participants (43\% and $44 \%$ of locals and immigrants, respectively) indicated holding a supervisory position. German and French immigrants were more likely to hold a supervisory position $(54.2 \%)$ than immigrants of other nationalities $(36.3 \%)$ or locals $(43 \%)$.

\section{Measures}

Descriptive statistics, correlations, and reliabilities (alpha coefficients) for the measures are reported in Table 1. Unless specified otherwise, a team of bilingual (French- and German-speaking) researchers translated scales that only existed in English into French and German. A second team of bilingual researchers independently verified the translations, to make sure that the German and French versions were equivalent. The entire questionnaire was pretested for comprehensibility of instructions and items in a sample of 50 adults between the ages of 25 and 55 (25 women; 25 German-speaking; 25 French-speaking).

Workplace incivility was measured with four items of the incivility measure developed by (Cortina, Magley, Williams, and Langhout, 2001; see Table 2, p.70), choosing those items that showed the highest factor loadings in the initial validation study. More specifically, participants were asked to indicate how often during the past 12 months they had been in a situation where any of their coworkers or supervisors (1) had put them down or was condescending, (2) paid little attention to their statement or little interest in their opinion, (3) made demeaning or derogatory remarks about them, or (4) addressed them in unprofessional terms, either publicly or privately. Responses were indicated on 5-point scales, ranging from $1=$ never to $5=$ most of the time.

Perceived discrimination was assessed with a single item, similar to the one of the Gallup Survey, analyzed by Avery, McKay and Wilson (2008). Participants were asked if they had been discriminated against, based on their ethnicity or nationality, within their workplace during the past 12 months. Responses were indicated as yes or no.

Table 1

Descriptives and Correlations of Study and Control Variables

\begin{tabular}{|c|c|c|c|c|c|c|c|c|c|c|c|}
\hline & $M(S D)$ & 1 & 2 & 3 & 4 & 5 & 6 & 7 & 8 & 9 & 10 \\
\hline 1. Age & $42.15(8.63)$ & - & & & & & & & & & \\
\hline 2. Gender & $0.49(0.50)$ & -.01 & - & & & & & & & & \\
\hline 3. Activity rate & $18.49(3.84)$ & $-.11^{* * *}$ & $-.51^{* * *}$ & - & & & & & & & \\
\hline 4. Organizational justice & $3.70(0.63)$ & .03 & -.01 & -.02 & $(.82)$ & & & & & & \\
\hline 5. Agreeableness & $3.62(0.45)$ & $.12^{* *}$ & $.22^{* *}$ & $-.17^{* *}$ & $.06^{*}$ & $(.70)$ & & & & & \\
\hline 6. Neuroticism & $2.55(0.59)$ & $-.09^{* * *}$ & $.15^{\text {*** }}$ & $-.10^{* *}$ & $-.30^{* *}$ & $-.12^{* *}$ & $(.83)$ & & & & \\
\hline 7. Incivility & $6.45(2.84)$ & -.00 & -.00 & $.06^{*}$ & $-.46^{* *}$ & $-.07^{* *}$ & $.22^{* * *}$ & $(.85)$ & & & \\
\hline 8. Perc. discrimination & $0.05(0.02)$ & $-.08^{*}$ & -.02 & .03 & $-.08^{* * *}$ & $-.08^{* *}$ & $.06^{*}$ & $.14^{* * *}$ & - & & \\
\hline 9. G/F immigrants & $0.08(0.27)$ & $-.08^{* *}$ & -.01 & .05 & .01 & -.03 & .03 & .05 & $.24^{* *}$ & - & \\
\hline 10. Other immigrants & $0.10(0.30)$ & $.07^{* * *}$ & .00 & $.07^{* * *}$ & -.03 & .00 & .02 & -.02 & $.13^{* *}$ & $-.10^{* *}$ & - \\
\hline
\end{tabular}

Note. Perc. discrimination $=$ Perceived workplace discrimination based on national or ethnic origin $(\operatorname{coded}$ as $0=n o$ and $1=y e s)$. G/F immigrants $=$ German or French immigrants $(0=$ local, $1=$ German or French immigrants $)$. Other immigrants = immigrant of nationalities other than German or French $(0=$ local, $1=$ other immigrants $)$. Gender was coded as $0=$ male, $1=$ female. Age was assessed in years. Activity rate was assessed in percentages $(1=$ $4 \%$ or less, $20=95-100 \%)$.

Reliabilities are shown in parentheses along the diagonal. For all correlations $n$ between 1,640 and 1,661.

${ }^{*} p<.05 .{ }^{* *} p<.01$. 
Control variables related to participants' personality, demographics, and work context were used to isolate the effects of immigrant status and nationality on incivility. First, we controlled for participant agreeableness and neuroticism because people low in agreeableness and high in neuroticism experience more incivility (Milam et al., 2009). Traits were assessed with the 12 itemscales of neuroticism (e.g., "I often get angry at the way people treat me") and agreeableness (e.g., "I tend to assume the best about people") of the French (Aluja, García, Rossier, \& García, 2005) and German versions (Borkenau \& Ostendorf, 1993; Schmitz, Hartkamp, Baldini, Rollnik, \& Tress, 2001) of the NEO Five Factor Inventory Revised (McCrae \& Costa, 2004). Participants responded on 5-point scales, ranging from 1 = strongly disagree to 5 = strongly agree. Second, we controlled for gender and age. Women experience more incivility than men (Cortina et al., 2011). Older employees are more discriminated against than their younger counterparts (Gordon \& Arvey, 2004), suggesting that they may become targets of selective incivility. Third, we controlled for participants' activity rate because being more present at the workplace may increase the probability to experience incivility. Activity rate was assessed with the following question: "What is your current rate of work? Take into account all current jobs and consider only paid activities." Responses were indicated on a 20-category scale, with each category spanning 5\% $(2.5 \mathrm{hr}$ per week) $(1=4 \%$ or less, $20=95 \%$ to $100 \%)$. Further, we controlled for organizational justice perceptions because low organizational justice is related to higher incidences of workplace aggression in general (Berry, Ones, \& Sackett, 2007). Organizational justice was assessed with the short version of the questionnaire by Colquitt (2001), validated by Elovainio et al. (2010), that covers distributive (two items, e.g., "Does your work situation reflect the effort you have put into your work?"), procedural (three items, e.g., "Have you been able to express your views and feelings during those procedures?") and interpersonal justice (three items, e.g., "Has your supervisor treated you with respect?"). For the interpersonal justice, we omitted one item ("Has your supervisor seemed to tailor his or her communications to individuals' specific needs?") because the item was difficult to translate adequately into French and German. Responses were indicated on 5-point scales $(1=$ to a small extent, $5=$ to a large extent $)$.

\section{Results}

Hypotheses were tested with multiple regressions, with age, gender, neuroticism, agreeableness, activity rate and organizational justice as control variables, ${ }^{1}$ nationality (locals vs. German and French immigrants vs. immigrants of other nationalities; dummy-coded) as predictor, and incivility sum scores as criterion. ${ }^{2}$ To test both the effect of immigrant status (being an immigrant vs. a local) and of immigrant nationality (being a German or French immigrant vs. an immigrant of another nationality) as stated in $\mathrm{H} 1$ and $\mathrm{H} 2$, two dummy codes for nationality were used that differed with respect to their reference category: locals, in Model 1, and immigrants of nationalities other than French or German in Model 2.

For the control variables, results of the final model showed that people with higher activity rates, those high in neuroticism and people perceiving less organizational justice reported more incivility. Further, as expected, German or French immigrant experi-
Table 2

Regression Results for Immigrant Status and Nationality, Predicting Experiences of Incivility at Work

\begin{tabular}{|c|c|c|c|c|}
\hline \multirow[b]{2}{*}{ Predictor } & \multicolumn{2}{|c|}{ Model 1} & \multicolumn{2}{|c|}{ Model 2} \\
\hline & $B$ & $S E$ & $B$ & $S E$ \\
\hline \multicolumn{5}{|l|}{ Control variables } \\
\hline Age & 0.01 & 0.01 & 0.01 & 0.01 \\
\hline Gender & 0.14 & 0.15 & 0.14 & 0.15 \\
\hline Activity rate & $0.05^{* * *}$ & 0.02 & $0.05^{* *}$ & 0.02 \\
\hline Organizational justice & $-1.96^{\text {*** }}$ & 0.10 & $-1.96^{* *}$ & 0.10 \\
\hline Neuroticism & $0.47^{\text {*** }}$ & 0.11 & $0.47^{* *}$ & 0.11 \\
\hline Agreeableness & -0.16 & 0.15 & -0.16 & 0.15 \\
\hline Locals vs. G/F immigrants & $0.46^{*}$ & 0.23 & - & - \\
\hline Locals vs. other immigrants & -0.24 & 0.21 & - & - \\
\hline \multicolumn{5}{|l|}{ Other immigrants vs. G/F } \\
\hline immigrants & - & - & $0.70^{*}$ & 0.29 \\
\hline Other immigrants vs. locals & - & - & 0.24 & 0.21 \\
\hline
\end{tabular}

Note. Adjusted $R^{2}=.23, F(8,1625)=60.79, p<.001 . \mathrm{G} / \mathrm{F}$ immigrants $=$ German or French immigrants. Other immigrants $=$ immigrant of nationalities other than German or French. Gender was coded as $0=$ male, $1=$ female. Age was assessed in years. Activity rate was assessed in percentages $(1=4 \%$ or less, $20=95-100 \%)$.

${ }^{*} p<.05$. *** $p<.01$.

enced more incivility $(M=6.89, S D=3.15)$ than locals $(M=$ $6.42, S D=2.85$ ) (see Model 1, Table 2). German and French immigrants also experienced more incivility than immigrants of other nationalities ( $M=6.31, S D=2.54$; see Model 2, Table 2). However, the latter did not experience more incivility than locals did.

In summary, $\mathrm{H} 1$ received partial support: Not all immigrants experienced more incivility than locals; only German and French immigrants did. In support of H2, German and French immigrants experienced more incivility than immigrants of other nationalities.

To explore relations between selective incivility and perceived workplace discrimination, we analyzed the joint impact of nationality and incivility on perceived discrimination, using logistic regressions, with perceived discrimination as criterion. As in the previous models, gender, age, activity rate, organizational justice, agreeableness, and neuroticism were entered as control variables. Nationality (dummy-coded, in two sets; see above) and incivility were entered as predictors. Among the control variables, only agreeableness was related to perceived discrimination, $B=-0.63$, $S E=0.31$, Odds Ratio $(\mathrm{OR})=0.54, \chi^{2}(9)=120.49, p<.001$, indicating that people low in agreeableness were more likely to report having been discriminated against. Among the main variables, immigrant status was related to perceived discrimination: Both being a German or French immigrant, $B=2.61, S E=0.31$,

\footnotetext{
${ }^{1}$ In preliminary analyses, we added supervisor status as a control variable. However, supervisor status was unrelated to incivility and to perceived discrimination, for locals, German and French immigrants, and other immigrants, all $r$ s between -.04 and $.07, n s$. Furthermore, including it in the regression models did not change results or improve the model nor did supervisor status emerge as a significant predictor. Thus, we did not include it in the final models.

${ }^{2}$ To make sure that regression coefficients were not biased by differences in sub-sample size, we re-ran the regression analyses generating $95 \%$ confidence intervals, based on 500 bootstrap samples. The pattern of results was identical the one reported in Table 2 or within the text.
} 
$\mathrm{OR}=13.47, p<.001$, and being an immigrant of another nationality, $B=1.99, S E=0.33, \mathrm{OR}=7.32, p<.001$, increased the probability to report having been discriminated against. Finally, incivility too was related to perceived discrimination: Experiencing more incivility increased the probability to report having been discriminated against, $B=0.17, S E=0.04$, $\mathrm{OR}=1.18$, $p<.001$.

\section{Discussion}

This study makes novel contributions to research on workplace discrimination. First, immigrant employees' experiences of incivility are shown for the first time using a representative sample, drawing attention to an increasingly important but often forgotten minority in the I/O psychology literature (Binggeli, Dietz, \& Krings, 2013). Second, it shows that subtle discrimination can be highly selective, mainly targeting those immigrant groups who are perceived as highly competitive and competent but as less likable. This result also underlines that discrimination against immigrants can only be understood when taking the diversity within this group into account. Third, by uncovering relations between experiences of incivility and perceived discrimination for the first time, it provides direct empirical evidence for the claim that selective incivility is indeed a form of discrimination. Finally, it is important to note that effects persisted above and beyond those of personality traits known to influence the experience of discriminatory behaviors.

More specifically, drawing on Cortina's (2008) model of subtle discrimination, we studied immigrants' incivility experiences, compared with locals. Results revealed that not all immigrants experienced more incivility than locals. Rather, it was mainly immigrant groups from the immediate neighboring countries, who have multiplied in number during the past decade, and who are very competitive and successful on the local labor market. However, competitiveness costs liking: These groups are perceived as highly competitive and competent but as lacking socioemotional warmth (Binggeli et al., 2013). As such, they receive similar stereotypes such as Asians in the United States do (Lin et al., 2005; Lee \& Fiske, 2006), suggesting that this group too may experience higher rates of workplace incivility. The combination of low warmth with high competence may be what makes these groups likely targets of subtle interpersonal discrimination: Whereas their high levels of competence are difficult to deny and (reluctantly or not) given credit for by locals, they are denigrated on warmth, that is, perceived as lacking in warmth and sociability, which may provide the basis for locals to treat them disrespectfully on an interpersonal level.

We also found that immigrant groups were more likely than locals to report having been discriminated against on the basis of their national or ethnic origin, at work, and that these perceptions were, in part, fueled by incivility experiences. This result has at least two implications. First, the linkage between incivility and perceived discrimination corroborates the claim that incivility can be a form of discrimination. It also suggests that while incivility is subtle from the instigator's perspective, it may be less subtle from the target's perspective. Second, it underlines the toxic nature of seemingly mild discourteous behaviors at work. Incivility experiences have various negative consequences for targets, for example, for their well-being or organizational commitment (Pearson \&
Porath, 2004). They also increase intentions to quit (Cortina et al., 2011). Incivility experiences combined with feelings of being discriminated against may further reinforce intentions to leave one's job and ultimately drive immigrants out of their workplaces.

We controlled for age and gender in our analyses because these groups are often targets of workplace discrimination. However, neither women nor older employees of our study experienced more incivility, which may be explained by several factors. First, unlike earlier studies testing the effects of gender and age (Cortina et al., 2011), we controlled for personality factors when predicting incivility. Indeed, neuroticism was closely related to reports of incivility, corroborating earlier findings (Milam et al., 2009), and underlining the necessity to control for stable individual differences, to isolate the effect of group membership on incivility. Second, analyses were based on a representative sample of the working age population and hence covered employees in a wide range of organizations and occupations. Incivility may be more pronounced in organizational contexts where older employees or women are perceived as "not belonging," because of social stereotypes, for example, successful women in male-dominated environments (Cortina, 2008; Cortina et al., 2011) or older employees in an organization characterized as young and dynamic (Diekman \& Hirnisey, 2007). Finally, the absence of higher incivility rates for older compared with younger employees is in line with earlier findings (Cortina et al., 2011). One explanation may be found in the age limit applied in this study (i.e., age 55), possibly excluding those who would experience the most age discrimination. Another explanation may lie in the older worker stereotype that describes older employees as incompetent (i.e., low in competence) but nice (i.e., high in warmth) (Krings, Sczesny, \& Kluge, 2011). Even though mixed stereotypes in general can fuel subtle interpersonal discrimination, results of our study and of other research suggest that the main drivers of interpersonal discrimination may reside with the combination of low warmth and high competence perceptions (Cuddy et al., 2008). Being perceived as incompetent but harmless and trustworthy may actually protect individuals from experiencing interpersonal mistreatments.

\section{Study Limitations and Future Research}

This study has limitations, and we would like to point out three. First, to participate, immigrants needed sufficient knowledge of one of the two largest national languages. Even though participation required only basic language skills as questions were kept simple, immigrants who did not speak these languages or only very poorly were not included. Further, only legal immigrants with a work permit were included. Consequently, illegal immigrants or immigrants that were less well integrated or well off, because of language problems, were not represented. Reaching these groups is a general and recurrent difficulty in survey research with immigrants (Laganá, Elcheroth, Penic, Kleiner, \& Fasel, 2013). However, they make up an important part of the immigrant population, and they are likely to experience discrimination. To attain a more complete picture of immigrants' work experiences, future research should invest more efforts to include them.

Second, effects of immigrant status on incivility and of incivility on perceived discrimination were significant but modest. This may be because of the fact that analyses were based on a large representative sample and hence included a wide array of possible 
influencing factors. For this reason, we included several relevant control variables related to participant demographics and employment context in the analyses. We also controlled for the impact of personality traits that were significantly related to the outcome variables. Thus, even though effects were modest, they are robust. Further, the significant, albeit modest effect of incivility on perceived discrimination underlines that incivility is a subtle form of discrimination. Compared with blatant discriminatory acts, incivility's subtle, ambiguous nature makes it more difficult for targets to recognize it as discriminatory. Future research should investigate both relations of perceived discrimination with experiences of subtle and of more blatant discriminatory acts, whereas the former relation should be stronger than the latter or emerge only after a certain time; that is, after repeated experiences of incivility.

Third, this study was carried out with national or ethnic groups in Switzerland. We are not aware of comparable studies in other countries so results should be replicated in a different context (e.g., in a different country, with the according highly competent but little likable immigrant groups).

\section{Conclusion}

Steadily increasing in number, immigrants play a progressively important role in local labor markets. Concurrently, they are a highly diverse group differing not only in terms of culture but also in terms of education and skill-level. For example, more recently, many countries have tried to attract larger numbers of skilled and educated immigrants, to combat shortages in highly skilled labor. Our research suggests that workplace discrimination experiences of these immigrants differ from those of earlier, less well-educated immigrants. Notably, the experience of subtle interpersonal discrimination of competitive immigrant groups from immediate neighboring countries draws researchers' and organizations' attention to a group that is typically overlooked. These groups are believed to integrate easily into the host country and labor market, and hence tend to be forgotten when designing measures to combat discrimination against immigrants. Further, by underlining the discriminatory nature of these seemingly harmless discourteous behaviors, it highlights the need for policymakers and organizations to discuss how to better protect employees from workplace discrimination. The law prohibits discrimination but focuses on blatant rather than on subtle discriminatory acts, ultimately leaving members of groups experiencing selective incivility without legal protection.

\section{References}

Akrami, N., Ekehammar, B., \& Araya, T. (2000). Classical and modern racial prejudice: A study of attitudes towards immigrants in Sweden. European Journal of Social Psychology, 30, 521-532. doi:10.1002/ 1099-0992(200007/08)30:4<521::AID-EJSP5>3.0.CO;2-N

Aluja, A., García, O., Rossier, J., \& García, L. F. (2005). Comparison of the NEO-FFI, the NEO-FFI-R and an alternative short version of the NEO-PI-R (NEO-60) in Swiss and Spanish samples. Personality and Individual Differences, 38, 591-604. doi:10.1016/j.paid.2004.05.014

Andersson, L. M., \& Pearson, C. M. (1999). Tit for tat? The spiraling effect of incivility in the workplace. Academy of Management Review, 24, 452-471. Retrieved from http://www.jstor.org/stable/259136

Avery, D. R., McKay, P. F., \& Wilson, D. C. (2008). What are the odds? How demographic similarity affects the prevalence of perceived em- ployment discrimination. Journal of Applied Psychology, 93, 235-249. doi:10.1037/0021-9010.93.2.235

Berry, C. M., Ones, D. S., \& Sackett, P. R. (2007). Interpersonal deviance, organizational deviance, and their common correlates: A review and meta-analysis. Journal of Applied Psychology, 92, 410-424. doi: 10.1037/0021-9010.92.2.410

Binggeli, S., Dietz, J., \& Krings, F. (2013). Immigrants: A forgotten minority. Industrial and Organizational Psychology: Perspectives on Science and Practice, 6, 107-113. doi:10.1111/iops.12019

Binggeli, S., Krings, F., \& Sczesny, S. (2013). Perceived competition explains regional differences in the stereotype content of immigrant groups. Social Psychology. doi:10.1027/1864-9335/a000160

Binggeli, S., Krings, F., \& Sczesny, S. (in press). Stereotype content of immigrant groups in Switzerland. Swiss Journal of Psychology.

Borkenau, P., \& Ostendorf, F. (1993). NEO-Fünf-Faktoren-Inventar (NEO-FFI) nach Costa und McCrae [NEO-Five-Factor Inventory according to Costa and McCrae]. Göttingen, Germany: Hogrefe.

Colquitt, J. A. (2001). On the dimensionality of organizational justice: A construct validation of a measure. Journal of Applied Psychology, 86, 386-400. doi:10.1037/0021-9010.86.3.386

Cortina, L. M. (2008). Unseen injustice: Incivility as modern discrimination in organizations. Academy of Management Review, 33, 55-75. doi:10.5465/AMR.2008.27745097

Cortina, L. M., Kabat-Farr, D., Leskinen, E. A., Huerta, M., \& Magley, V. J. (2011). Selective incivility as modern discrimination in organizations: Evidence and impact. Journal of Management. Advance online publication. doi:10.1177/0149206311418835

Cortina, L. M., Lonsway, K. L., Magley, V. J., Freeman, L. V., Collinsworth, L. L., Hunter, M., \& Fitzgerald, L. F. (2002). What's gender got to do with it? Incivility in the federal courts. Law and Social Inquiry, 27, 235-270. doi:10.1111/j.1747-4469.2002.tb00804.x

Cortina, L. M., Magley, V. J., Williams, J. H., \& Langhout, R. D. (2001). Incivility in the workplace: Incidence and impact. Journal of Occupational Health Psychology, 6, 64-80. doi:10.1037/1076-8998.6.1.64

Cuddy, A. J., Fiske, S. T., \& Glick, P. (2007). The BIAS map: Behaviors from intergroup affect and stereotypes. Journal of Personality and Social Psychology, 92, 631-648. doi:10.1037/0022-3514.92.4.631

Cuddy, A. J., Fiske, S. T., \& Glick, P. (2008). Warmth and competence as universal dimensions of social perception: The stereotype content model and the BIAS map. Advances in Experimental Social Psychology, 40, 61-149. doi:10.1016/S0065-2601(07)00002-0

Diekman, A. B., \& Hirnisey, L. (2007). The effect of context on the silver ceiling: A role congruity perspective on prejudiced responses. Personality and Social Psychology Bulletin, 33, 1353-1366. doi:10.1177/ 0146167207303019

Dipboye, R. L., \& Halverson, S. K. (2004). Subtle (and not so subtle) discrimination in organizations. In R. W. Griffin \& A. O'Leary-Kelly (Eds.), The dark side of organizational behavior (pp. 131-158). San Francisco, CA: Jossey-Bass.

Eckes, T. (2002). Paternalistic and envious gender stereotypes: Testing predictions from the stereotype content model. Sex Roles, 47, 99-114. doi:10.1023/A:1021020920715

Elovainio, M., Heponiemi, T., Kuusio, H., Sinervo, T., Hintsa, T., \& Aalto, A. (2010). Developing a short measure of organizational justice: A multi-sample health professionals study. Journal of Occupational and Environmental Medicine, 52, 1068-1074. doi:10.1097/JOM .0b013e3181f8447c

Esses, V. M., Dovidio, J. F., Jackson, L. M., \& Armstrong, T. L. (2001). The immigration dilemma: The role of perceived group competition, ethnic prejudice, and national identity. Journal of Social Issues, 57, 389-412. doi:10.1111/0022-4537.00220

Fiske, S. T., Cuddy, A. J., Glick, P., \& Xu, J. (2002). A model of (often mixed) stereotype content: Competence and warmth respectively follow 
from perceived status and competition. Journal of Personality and Social Psychology, 82, 878-902. doi:10.1037/0022-3514.82.6.878

Gaertner, S. L., \& Dovidio, J. F. (1986). The aversive form of racism. In J. F. Dovido \& S. L. Gaertner (Eds.), Prejudice, discrimination, and racism (pp. 61-89). Orlando, FL: Academic Press.

Glick, P., \& Fiske, S. T. (1996). The ambivalent sexism inventory: Differentiating hostile and benevolent sexism. Journal of Personality and Social Psychology, 70, 491-512. doi:10.1037/0022-3514.70.3.491

Glick, P., \& Fiske, S. T. (2001). Ambivalent stereotypes as legitimizing ideologies: Differentiating paternalistic and envious prejudice. In J. Jost \& B. Major (Eds.), The psychology of legitimacy (pp. 278-306). Cambridge, England: Cambridge University Press.

Gordon, R. A., \& Arvey, R. D. (2004). Age bias in laboratory and field settings: A meta-analytic investigation. Journal of Applied Social Psychology, 34, 468-492. doi:10.1111/j.1559-1816.2004.tb02557.x

Hebl, M. R., Foster, J. B., Mannix, L. M., \& Dovidio, J. F. (2002). Formal and interpersonal discrimination: A field study of bias toward homosexual applicants. Personality and Social Psychology Bulletin, 28, 815825. doi:10.1177/0146167202289010

Jasinskaja-Lahti, I., Liebkind, K., \& Perhoniemi, R. (2007). Perceived ethnic discrimination at work and well-being of immigrants in Finland: The moderating role of employment status and work-specific grouplevel control beliefs. International Journal of Intercultural Relations, 31, 223-242. doi:10.1016/j.ijintrel.2006.02.003

Kravitz, D. A., \& Klineberg, S. L. (2000). Reactions to two versions of affirmative action among Whites, Blacks, and Hispanics. Journal of Applied Psychology, 85, 597-611. doi:10.1037/0021-9010.85.4.597

Krings, F., \& Olivares, J. (2007). At the doorstep to employment: Discrimination against immigrants as a function of applicant ethnicity, job type, and rater's prejudice. International Journal of Psychology, 42, 406-417. doi:10.1080/00207590701251721

Krings, F., Sczesny, S., \& Kluge, A. (2011). Stereotypical inferences as mediators of age discrimination: The role of competence and warmth. British Journal of Management, 22, 187-201. doi:10.1111/j.1467-8551 .2010.00721.x

Laganá, F., Elcheroth, G., Penic, S., Kleiner, B., \& Fasel, R. (2013). National minorities and their representation in Swiss Surveys (II): Which practices make a difference? Quality and Quantity, 47, 12871314. doi:10.1007/s11135-011-9591-1

Lee, T. L., \& Fiske, S. T. (2006). Not an outgroup, not yet an ingroup: Immigrants in the stereotype content model. International Journal of Intercultural Relations, 30, 751-768. doi:10.1016/j.ijintrel.2006.06.005

Liebig, T., Kohls, S., \& Krause, K. (2012). The labour market integration of immigrants and their children in Switzerland. OECD Social, Employment and Migration Working Papers, No. 128, OECD Publishing. doi:10.1787/5k9fjjs1m2d2-en

Lin, M. H., Kwan, V. S. Y., Cheung, A., Fiske, S. T. (2005). Stereotype Content Model explains prejudice for an envied outgroup: Scale of
anti-Asian American stereotypes. Personality and Social Psychology Bulletin, 31, 34-47. doi:10.1177/0146167204271320

McConahay, J. B. (1986). Modern racism, ambivalence, and the modern racism scale. In J. F. Dovidio \& S. L. Gaertner (Eds.), Prejudice, discrimination, and racism (pp. 91-125). San Diego, CA: Academic press.

McCrae, R. R., \& Costa, P. T. (1987). Validation of the five-factor model of personality across instruments and observers. Journal of Personality and Social Psychology, 52, 81-90. doi:10.1037/0022-3514.52.1.81

McCrae, R. R., \& Costa, P. T. (2004). A contemplated revision of the NEO Five-Factor Inventory. Personality and Individual Differences, 36, 587596. doi:10.1016/S0191-8869(03)00118-1

Milam, A. C., Spitzmueller, C., \& Penney, L. M. (2009). Investigating individual differences among targets of workplace incivility. Journal of Occupational Health Psychology, 14, 58-69. doi:10.1037/a0012683

OECD. (2012a). International migration outlook 2012. OECD Publishing. Retrieved from doi:10.1787/migr_outlook-2012-en

OECD. (2012b). Key statistics on migration in OECD countries. Retrieved from http://www.oecd.org/document/4/0,3746,en_2649_37415_ 48326878_1_1_1_37415,00.html

Pearson, C. M., \& Porath, C. L. (2004). On incivility, its impact, and directions for future research. In R. W. Griffin \& A. O'Leary-Kelly (Eds.), The dark side of organizational behavior (pp. 403-426). San Francisco, CA: Jossey-Bass.

Petersen, L. E., \& Dietz, J. (2005). Prejudice and enforcement of workforce homogeneity as explanations for employment discrimination. Journal of Applied Social Psychology, 35, 144-159. doi:10.1111/j.1559-1816.2005 .tb02097.x

Pettigrew, T. F., \& Meertens, R. W. (1995). Subtle and blatant prejudice in western Europe. European Journal of Social Psychology, 25, 57-75. doi:10.1002/ejsp.2420250106

Pew Research Center. (2012). The rise of Asian Americans. Retrieved from http://www.pewsocialtrends.org/2012/06/19/the-rise-of-asian-americans/

Schmitz, N., Hartkamp, N., Baldini, C., Rollnik, J., \& Tress, W. (2001). Psychometric properties of the German version of the NEO-FFI in psychosomatic outpatients. Personality and Individual Differences, 31, 713-722. doi:10.1016/S0191-8869(00)00173-2

Sibley, C. G. (2011). The BIAS-Treatment Scale (BIAS-TS): A measure of the subjective experience of active and passive harm and facilitation. Journal of Personality Assessment, 93, 300-315. doi:10.1080/00223891 .2011 .559389

Swim, J. K., Aikin, K. J., Hall, W. S., \& Hunter, B. A. (1995). Sexism and racism: Old-fashioned and modern prejudices. Journal of Personality and Social Psychology, 68, 199-214. doi:10.1037/0022-3514.68.2.199

Swiss Federal Statistics Office. (2012). Panorama: Employment and income from employment. Retrieved from http://www.bfs.admin.ch/bfs/ portal/en/index/themen/03/01/pan.html 